\title{
The Impact of Technology M\&A on High-Tech Enterprise Innovation Ability: Based on the Moderating Effect of Enterprise Culture
}

\author{
$\mathrm{Xi} \mathrm{Yu*}$ \\ School of Economics and Management, Beijing Jiaotong University, China 100044 \\ *Corresponding author. Email:20120714@bjtu.edu.cn
}

\begin{abstract}
Technology M\&A (Mergers and Acquisitions) is an effective way for enterprises to acquire external knowledge and technology quickly. Many high-tech enterprises intend to make up for the lack of innovation ability through technology M\&A. Also, the enterprise culture will act on the M\&A. This paper mainly studies the impact of technology M\&A on the innovation ability of high-tech enterprises, and the effect of enterprise culture on the relationship between them. On the basis of relevant theories and literatures, this paper combs and analyses the relationship among technology $\mathrm{M} \& \mathrm{~A}$, enterprise innovation ability and enterprise culture, and puts forward research hypotheses. Taking $307 \mathrm{M} \& \mathrm{~A}$ events of high-tech enterprises of China A-share listed companies as samples, this paper uses multiple regression method to conduct empirical test. The results show that: Technology M\&A can improve the innovation ability of high-tech enterprises, and the innovation culture of the acquiring enterprise has the positive moderating effect between technology M\&A and innovation ability.
\end{abstract}

Keywords: Technology M\&A, Innovation ability, Enterprise culture.

\section{INTRODUCTION}

Innovation ability is an important factor that makes an enterprise stand out. High-tech enterprises regard their core independent intellectual property rights as their main competitiveness, so they pay more attention to innovation. Technology M\&A is a M\&A activity whose main purpose is to obtain technical resources. More and more high-tech enterprises are inclined to make up the gap in innovation ability through technology M\&A. However, there is still no unified conclusion on the relationship between technology M\&A and enterprise innovation ability. Ahuja and Katila (2001) [1] found that in technology M\&A, the absolute size of the acquired knowledge base improved innovation performance, while the relative size of the acquired knowledge base reduced innovation performance. Cloodt et al. (2006) [2] found that the acquired knowledge base would promote the innovation ability of enterprises after technology M\&A in the first few years, but the large size of the acquired knowledge base might inhibit the innovation ability after a few years. The existing researches on the role of technology M\&A in innovation is mixed, whether high-tech enterprises should carry out technology M\&A for innovation purposes still needs scientific research results as a reference.

The concept of enterprise culture was proposed by Schein (1984) [3], who believed that enterprise culture was an important determinant of enterprise behaviour and performance. As an element of enterprise culture, innovation culture will affect the innovation behaviour of enterprises. Some scholars have studied the influence of culture on enterprise innovation and M\&A performance. Hurley and Hult (1998) [4] believed that the higher the innovation culture level, the stronger the enterprise's adaptability and innovation ability, and the more the enterprise emphasized learning and development. Kaasa and Vadi (2010) [5] believed that culture was the foundation of innovation. In terms of M\&A, Kavanagh and Ashkanasy (2006) [6] found that the adjustment of culture and management mode after acquisition had a significant impact on the performance. Improper adjustment would hinder the integration of enterprises. It can be inferred that whether the acquiring enterprise has innovation culture will affect its behaviour in technology M\&A, which in turn may 
influence the effect of technology M\&A on the enterprise innovation ability.

This paper attempts to find out the relationship between technology $\mathrm{M} \& \mathrm{~A}$ and enterprise innovation ability, and further explores the influence of enterprise culture on the relationship between them, so as to provide references for high-tech enterprises about technology M\&A, innovation development and culture shaping.

\section{THEORETICAL BACKGROUND AND HYPOTHESES}

This paper combs the theoretical background of technology M\&A, innovation ability and enterprise culture, and puts forward research hypotheses.

\subsection{The Impact of Technology M\&A on High- tech Enterprise Innovation Ability}

According to resource-based theory, knowledge is one of the main resources of an enterprise. The knowledge that an enterprise possesses and the ability to create and apply knowledge are the competitive advantages, which can bring a positive impact on the innovation. Ahuja and Katila (2001) [1] proposed that company could acquire technical knowledge in a short time through technology M\&A, which would promote innovation. Zhang Xueyong et al. (2017) [7] believed that technology M\&A would produce innovation synergies, thus improving the technological capability and R\&D level of enterprises. It can be speculated that high-tech enterprises can acquire technical knowledge from the outside quickly through technology M\&A, so that they can better apply knowledge for innovation and improve their innovation ability.

Hypothesis 1 is put forward: Technology M\&A can improve the innovation ability of high-tech enterprises.

\subsection{The Moderating Effect of the Acquiring Enterprise Culture}

The value created by M\&A is determined by the absorption of resources and the effect of integration. Datta et al. (1992) [8] proposed that innovation culture had an important impact on the selection and transaction mode of M\&A, as well as the integration of resources. Thornberry (2003) [9] believed that innovation culture would encourage and guide innovative behaviour. Thus, if the acquiring enterprise has innovation culture, its innovation behaviour will be supported more, and the implementation of technology M\&A will be smoother and more effective, so that the promotion effect of technology M\&A on innovation ability will be strengthened.
Hypothesis 2 is put forward: The innovation culture of the acquiring enterprise has the positive moderating effect between technology M\&A and innovation ability.

\section{METHODS}

The empirical design relates the technology M\&A and innovation ability and explores the moderating effect of enterprise culture.

\subsection{Sample}

This study selects the M\&A events of Shenzhen and Shanghai A-share listed companies from 2013 to 2015, which can ensure the data are complete (the research needs data from one year before the acquisition to two years after the acquisition). This study determines whether the company is a high-tech enterprise based on the recognition of enterprise qualification in the public announcement. The M\&A events of the high-tech enterprise are selected as samples, and further screening is conducted: (1) Exclude unfinished events; (2) Exclude special treatment events; (3) Exclude the events in which the acquiring enterprises obtain less than $20 \%$ stock rights; (4) Only keep the company's first M\&A event in that year; (5) Exclude incomplete samples. Finally got 307 samples. The data are from Wind database, CSMAR database, and the official websites of companies.

\subsection{Variables}

The dependent variable is enterprise innovation ability, measured by the growth rate of the number of patent applications, marked as Patent. Referring to Wang Wanqiu and Ma Hongjun (2020) [10], this paper calculates the average number of patent applications from the first year to two years after the acquisition, and uses the average to subtract the number of patent applications in the year before acquisitions, then divides the value by the patent applications number in the year before acquisitions to get the growth rate.

The independent variable is technology M\&A, marked as MA. Referring to Ahuja and Katila (2001) [1], if the public information about M\&A mentions that the main purpose is to acquire technology, it will be considered as a technology M\&A and the assignment is 1 , otherwise the assignment is 0 .

The moderator variable is innovation culture, marked as Innovation. Referring to Zhang Yuming et al. (2016) [11], if the description of enterprise culture on the official website contains words such as "innovation, creation, research and development", and its meaning is indeed so, the enterprise is considered to have the innovative culture and the assignment is 1 , otherwise the assignment is 0 . 
In this study, the following variables are controlled: (1)Patbase, measured by the number of effective patents of acquiring enterprise before the acquisition; (2)RD, take the average $R \& D$ ratio $(R \& D$ investment divided by operating income) from the first year to two years after the acquisition. If the average is greater than the $\mathrm{R} \& \mathrm{D}$ ratio of the year before the acquisition, the assignment is 1; otherwise the assignment is 0 ; (3) Asset, measured by the logarithm of the total assets of the acquiring enterprise before the acquisition. (4)Eps, measured by the earnings per share of the acquiring enterprise before the acquisition. (5)Ider, measured by the percentage of the independent directors in the total directors of the acquiring enterprise in the year of acquisition.

\subsection{Model}

The basic Model (1) is formed with dependent variable Patent and control variables.

Patent $=\beta_{0}+\beta_{1}$ Patbase $+\beta_{2} R D+\beta_{3}$ Asset + $\beta_{4}$ Eps $+\beta_{5}$ Ider $+\varepsilon$

On the basis of Model (1), independent variable $M A$ is added to form Model (2) to examine the impact of technology M\&A on the innovation ability of high-tech enterprises.

Patent $=\beta_{0}+\beta_{1} M A+\beta_{2}$ Patbase $+\beta_{3} R D+$
$\beta_{4}$ Asset $+\beta_{5}$ Eps $+\beta_{6}$ Ider $+\varepsilon$

According to Wen Zhonglin et al. (2005)[12], if the moderator variable is a dummy variable, the samples should be grouped according to its value, and regression analysis should be performed respectively. If the regression coefficients are significantly different, it means that there is moderating effect. Thus, in this study, the samples are grouped and regressed on the basis of Model (2). By comparing the regression coefficients of the group with innovative culture and the group without innovative culture, the moderating effect was tested.

\section{RESULTS}

In this paper, the research hypotheses are tested by variables descriptive statistics, multiple regression and grouping regression.

\subsection{Descriptive Statistics of Variables}

According to the statistical results of samples in Table 1: (1) The highest growth rate of patent applications after acquisition is $183.3 \%$, and the lowest is- $94.1 \%$. The large gap indicates that there is a big difference in the change of innovation ability; (2) Among the 307 M\&A samples, technology M\&A events accounted for relatively few; (3) Nearly half of the acquiring enterprises do not have innovation culture.

Table 1. Descriptive statistics of variables

\begin{tabular}{|c|c|c|c|c|}
\hline & Mean & S.D. & Min. & Max. \\
\hline Patent & -0.005 & 0.583 & -0.941 & 1.833 \\
\hline MA & 0.098 & 0.297 & 0.000 & 1.000 \\
\hline Innovation & 0.570 & 0.496 & 0.000 & 1.000 \\
\hline Patbase & 77.746 & 95.612 & 1.000 & 868.000 \\
\hline RD & 0.801 & 0.400 & 0.000 & 1.000 \\
\hline Asset & 21.557 & 0.982 & 19.541 & 25.041 \\
\hline Eps & 0.192 & 0.329 & -0.450 & 1.950 \\
\hline Ider & 0.378 & 0.052 & 0.273 & 0.600 \\
\hline
\end{tabular}

Note: According to the output results of Stata15.0 (the same below).

\subsection{Multiple Regression Explaining the Impact of Technology M\&A on Enterprise Innovation Ability}

This paper explores the impact of technology M\&A on the innovative ability of high-tech enterprises. Use the overall samples to perform regression analysis on Model (1) that only contains control variables, and then perform regression analysis on Model (2) that includes independent variable $M A$. According to the results in Table 2, the regression coefficient between $M A$ and Patent is 0.6842 at $1 \%$ significant, indicating that those two are significantly positively correlated. Hypothesis 1 has been verified that technology M\&A can improve the innovation ability of high-tech enterprises.

Table 2. The impact of technology M\&A on enterprise innovation ability

\begin{tabular}{|c|c|c|c|c|}
\hline & \multicolumn{2}{|c|}{ Patent- Model (1) } & \multicolumn{2}{c|}{ Patent- Model (2) } \\
\hline & Coef. & $\mathrm{z}$ & Coef. & $\mathrm{z}$ \\
\hline MA & & & $0.6842^{* * *}$ & 7.85 \\
\hline Patbase & $-0.0008^{* * *}$ & -2.99 & $-0.0008^{* * *}$ & -3.58 \\
\hline RD & $0.5683^{* * *}$ & 11.41 & $0.4795^{* * *}$ & 9.65 \\
\hline Asset & 0.0264 & 0.66 & 0.0551 & 1.44 \\
\hline Eps & 0.0046 & 0.04 & 0.0642 & 0.64 \\
\hline Ider & 0.6126 & 0.98 & 0.4628 & 0.83 \\
\hline Constant & -1.1990 & -1.29 & $-1.7681 * *$ & -2.00 \\
\hline R-sq & 0.1876 & & 0.3047 & \\
\hline Chi-sq & $153.37 * * *$ & & $242.81 * * *$ & \\
\hline Obs & 307 & & 307 & \\
\hline
\end{tabular}

Note: $* \mathrm{p}<0.10, * * \mathrm{p}<0.05, * * * \mathrm{p}<0.01$.

\subsection{Grouping Regression Explaining the Moderating Effect of Innovation Culture}

In order to further test the moderating effect of innovation culture between technology $\mathrm{M} \& \mathrm{~A}$ and 
enterprise innovation ability, this paper distinguishes the samples with innovation culture and those without innovation culture, and performs regression analysis on the two groups. According to the results in Table 3, the regression coefficient of $M A$ in the group with innovation culture is 0.7603 at $1 \%$ significant, and without innovation culture is 0.6313 at $1 \%$ significant. The regression coefficient of samples with innovation culture is higher, which means that the innovation ability of the enterprise with innovation culture is improved more. Hypothesis 2 has been verified that the innovation culture of the acquiring enterprise has the positive moderating effect between technology M\&A and innovation ability.

Table 3. The moderating effect of innovation culture

\begin{tabular}{|c|c|c|c|c|}
\hline & \multicolumn{2}{|c|}{$\begin{array}{c}\text { Patent } \\
\text { (with innovation } \\
\text { culture) }\end{array}$} & \multicolumn{2}{c|}{$\begin{array}{c}\text { Patent } \\
\text { (without innovation } \\
\text { culture) }\end{array}$} \\
\hline & Coef. & $\mathrm{z}$ & Coef. & $\mathrm{t}$ \\
\hline MA & $0.7603 * * *$ & 6.75 & $0.6313 * * *$ & 4.78 \\
\hline Patbase & $-0.0009 * *$ & -2.52 & $-0.0008 * * *$ & -2.80 \\
\hline RD & $0.4427 * * *$ & 6.13 & $0.4789 * * *$ & 6.61 \\
\hline Asset & 0.0789 & 1.40 & 0.0106 & 0.27 \\
\hline Eps & 0.0835 & 0.64 & -0.0251 & -0.19 \\
\hline Ider & 0.2122 & 0.29 & 0.7711 & 0.92 \\
\hline Constant & $-2.1597 *$ & -1.68 & -0.9070 & -1.00 \\
\hline R-sq & 0.2922 & & 0.3338 & \\
\hline Chi-sq/F & $140.27 * * *$ & & $17.28 * * *$ & \\
\hline Obs & 175 & & 132 & \\
\hline
\end{tabular}

Note: $* \mathrm{p}<0.10, * * \mathrm{p}<0.05, * * * \mathrm{p}<0.01$.

\section{ROBUSTNESS TEST}

In order to test the robustness of the results, this paper changes the measurement of the dependent variable, replaces the growth rate of the number of patent applications with the growth rate of the number of patents granted, and performs regression analysis again. According to the results of Table 4 and Table 5, the conclusions have not changed, indicating that the results of this study are robust.
Table 4. Test the impact of technology M\&A on enterprise innovation ability

\begin{tabular}{|c|c|c|c|c|}
\hline & \multicolumn{2}{|c|}{ Patent1- Model (1) } & \multicolumn{2}{c|}{ Patent1- Model (2) } \\
\hline & Coef. & $\mathrm{t}$ & Coef. & $\mathrm{t}$ \\
\hline MA & & & $0.8163^{* * *}$ & 4.36 \\
\hline Patbase & $-0.0211^{* * *}$ & -3.28 & $-0.0165^{* * *}$ & -3.27 \\
\hline RD & $0.5236^{* * *}$ & 3.82 & $0.4698^{* * *}$ & 4.59 \\
\hline Asset & 0.0823 & 0.18 & 0.0373 & 0.09 \\
\hline Eps & 0.0565 & 0.22 & 0.1910 & 0.76 \\
\hline Ider & $4.5366^{* *}$ & 2.31 & $4.5628 * *$ & 2.43 \\
\hline Constant & -2.1534 & -0.23 & -1.6158 & -0.18 \\
\hline R-sq & 0.4300 & & 0.5455 & \\
\hline F & $8.36 * * *$ & & $16.67 * * *$ & \\
\hline Obs & 307 & & 307 & \\
\hline
\end{tabular}

Note: $* \mathrm{p}<0.10, * * \mathrm{p}<0.05, * * * \mathrm{p}<0.01$

Table 5. Test the moderating effect of innovation culture

\begin{tabular}{|c|c|c|c|c|}
\hline & \multicolumn{2}{|c|}{$\begin{array}{c}\text { Patent1 } \\
\text { (with innovation } \\
\text { culture) }\end{array}$} & \multicolumn{2}{c|}{$\begin{array}{c}\text { Patent1 } \\
\text { (without innovation } \\
\text { culture) }\end{array}$} \\
\hline & Coef. & $\mathrm{t}$ & Coef. & $\mathrm{z}$ \\
\hline MA & $0.8804 * * *$ & 4.11 & $0.7219^{* * *}$ & 5.09 \\
\hline Patbase & $-0.0204 * * *$ & -4.59 & $-0.0007 * *$ & -2.40 \\
\hline RD & 0.2342 & 1.33 & $0.4836 * * *$ & 5.43 \\
\hline Asset & 0.5752 & 1.25 & $0.1189 *$ & 1.75 \\
\hline Eps & 0.3474 & 1.27 & -0.0898 & -0.66 \\
\hline Ider & $6.2002 * * *$ & 3.50 & 0.9324 & 0.85 \\
\hline Constant & -13.3518 & -1.38 & $-3.2105 * *$ & -1.98 \\
\hline R-sq & 0.6628 & & 0.2899 & \\
\hline F/Chi-sq & $17.26 * * *$ & & $95.57 * * *$ & \\
\hline Obs & 175 & & 132 & \\
\hline
\end{tabular}

Note: $* \mathrm{p}<0.10, * * \mathrm{p}<0.05, * * * \mathrm{p}<0.01$.

\section{CONCLUSION}

This paper takes the M\&A events of high-tech companies in China's A-share listed companies as the samples. Through overall regression analysis and group regression analysis, it explores the impact of technology M\&A on the innovation ability of high-tech enterprises and the moderating effect of enterprise culture between them. It is concluded that: (1) Technology M\&A can improve the innovation ability of high-tech enterprises. (2) The innovation culture of the acquiring enterprise has the positive moderating effect between technology M\&A and innovation ability, that is, the innovation ability of the enterprises with innovation culture will be improved more by technology M\&A. 
The conclusions can help the enterprises in some ways: (1) This paper finds that technology M\&A can improve the innovation ability of high-tech enterprises, but the number of technology M\&A events is relatively less. Thus, it may be better for enterprises to realize innovation through technology M\&A. (2) This paper finds that innovation culture will positively affect the innovation effect of technology M\&A, but at present, nearly half of the high-tech enterprises in China do not have innovation culture. Thus, it is necessary for enterprise to create innovative culture and implement it.

This paper makes up for some deficiencies of existing studies, but it still has the following shortcomings: (1) The sample data is not new and sufficient enough. When the database is updated, the samples period can be longer. (2) It would be better if the moderator variable Innovation could be measured in more detailed and objective ways, such as measuring cultural strength or using questionnaires.

\section{REFERENCES}

[1] Ahuja G, Katila R. Technological Acquisitions and the Innovation Performance of Acquiring Firms: A Longitudinal Study. Strategic Management Journal, 2001, (22): 197 220.

[2] Cloodt M, Hagedoorn J, Van Kranenburg $H$. Mergers and Acquisitions: Their Effect on the Innovative Performance of Companies in Hightech Industries. Research Policy, 2006, 35(5): 642 654.

[3] Schein E H. Coming to a New Awareness of Organizational Culture. Sloan Management Review, 1984, 25(2): 3 16.

[4] Hurley R F, Hult G T. Innovation, Market Orientation, and Organizational Learning: An Integration and Empirical Examination. The Journal of Marketing, 1998, 62(7): 42 54.
[5] Kaasa A, Vadi M. How Does Culture Contribute to Innovation? Evidence from European Countries. Economics of Innovation and New Technology, 2010, 19(7): 583 604.

[6] Kavanagh M H, Ashkanasy N M. The Impact of Leadership and Change Management Strategy on Organizational Culture and Individual Acceptance of Change During A Merger. British Journal of Management, 2006, 17(SI): 81 103.

[7] ZHANG Xueyong, LIU Yiyi, LUO Dan, CHEN Rui. The Impact of Innovation on Acquisition Performance. Journal of Financial Research, 2017, (3): 159 175.

[8] Datta D K, Pinches G E, Narayanan V K. Factors Influencing Wealth Creation from Mergers and Acquisitions: A Meta-analysis. Strategic Management Journal, 1992, 13(1): 67 84.

[9] Thornberry, Dvpgressman Mac. Fostering a culture of Innovation. Proceedings of the United States Naval Institute, 2003, 129(4): 44 48.

[10] WANG Wanqiu, MA Hongjun. Technology Proximity, R\&D Investment and Innovation Performance in Technology Mergers and Acquisitions_-From a Perspective of Corporate Life Cycle. Management Review, 2020, 32(6): 104 113.

[11] ZHANG Yuming, LI Rong, MIN Yijie. Does the Innovation Culture Promote R\&D Investment? Studies in Science of Science, 2016, 34(9): 1417 1425.

[12] WEN Zhonglin, HOU Jietai, ZHANG Lei. A Comparison of Moderator and Mediator and their Applications. Acta Psychologica Sinica, 2005, 37(2): 268 274 